\title{
KAJIAN TEORITIK PENGARUH GEOMETRI DAN BENTUK SUDU TERHADAP UNJUK KERJA TURBIN PROPELLER
}

\author{
Ari Prasetyo, Dwi Aries Himawanto ${ }^{1}$ \\ Jurusan Teknik Mesin \\ Universitas Sebelas Maret Surakarta \\ Email : ${ }^{1}$ wwiarieshimawanto $@$ gmail.com
}

\begin{abstract}
Electrical energy is one of the primary needs of Indonesian society that continues to increase. However, until now most of the electricity needs are still supplied by fossil fuel power plants. The fossil energy dependence affects the high cost of distributing electricity to remote areas. The picohydro power plant using propeller turbines is one solution for remote areas. The purpose of this paper is to conduct a theoretical study to obtain optimal propeller blade design with relatively easy design method. Based on the study results obtained geometry and design of turbine propeller that can produce efficiency $73,9 \%$ with head water $1,75 \mathrm{~m}$ and debit $64 \mathrm{l} / \mathrm{s}$. While the propeller turbine design is the diameter of the turbine $200 \mathrm{~mm}$ the number of blades 5 , and the inlet runner tip $65^{\circ}$.
\end{abstract}

Keywords : Turbin propeller, sudu, efisiensi, picohydro

1. Pendahuluan

Energi listrik merupakan salah satu kebutuhan primer manusia yang terus mengalami peningkatan. Hal itu disebabkan oleh kegiatan manusia yang semakin banyak dan pertumbuhan populasi manusia yang terus meningkat secara signifikan khususnya di Indonesia. Saat ini, sebagian besar kebutuhan tenaga listrik di Indonesia masih dipasok oleh pembangkit listrik berbahan bakar fosil. Urutan kebutuhan energy di Indonesia adalah minyak bumi menduduki peringkat tertinggi, yaitu $51,66 \%$, gas alam peringkat kedua, sebesar $28,57 \%$, sisanya dipasok oleh energi minyak sebesar $15,34 \%$, dan enegi terbarukan $4,43 \%$ [1]. Ketergantungan terhadap energi fosil dan minimnya pemanfaatan energi terbarukan merupakan salah satu kelemahan dalam penerapan kebijakan energi [2]. Salah satu persoalan dalam penditribusian listrik adalah jarak sumber listrik dengan konsumen yang jauh khususnya di daerah terpencil. Padahal potensi sumber daya alam yang ada di Indonesia dapat dimanfaatkan menjadi pembangkit listrik skala mini/picohydro. Walaupun pada keadaan aliran rendah air tetap dapat diginakan untuk memutar sebuah turbin air. Hal ini dikarenakan air mempunyai momentum yang lebih besar dibandingkan dengan fluida lain [3].

Pembangkit listrik tenaga picohydro (PLTPH) adalah pembangkit listrik yang menghasilkan daya keluaran maksimal sebesar $5 \mathrm{~kW}$ [4]. Penelitian tentang turbin propeller untuk mengembangkan pembangkit listrik tenaga picohydro telah banyak dilakukan oleh Alexander [5] dan Masjuri [6]. Vertical Axis Water Turbine (VAWT) dengan memakai turbin bertipe drag telah diteliti oleh Chen [7]. Penelitian ini menghasilkan daya sebesar $88,2 \mathrm{~W}$ dengan pressure drop sebesar $1,5 \mathrm{~m} / \mathrm{s}$. Myint [8] melakukan desain dan studi simulasi tentang aliran pada blade turbin propeller dengan menggunakan aplikasi Flow Simulation Solidworks.

Penelitian tersebut menggunakan data input mass flow rate sebesar $1,499 \mathrm{~m}^{3} / \mathrm{s}$ dan menghasilkan distribusi kecepatan pada turbin hingga $10,949 \mathrm{~m} / \mathrm{s}$. Selanjutnya ilmuwan dari Thailand, Nuantong, dkk melakukan penelitian dengan metode simulasi untuk mengetahui performa turbin propeller kaplan. Turbin dengan sudut guide vane $70^{\circ}$, sudut twist turbin sebesar $25^{\circ}$ dan sudut sudu turbin sebesar $32^{\circ}$ dapat menghasilkan tekanan maksimum $217 \mathrm{kPa}$ dan tekanan minimum $-581 \mathrm{kPa}$ [9]. 
Penelitian tentang propeller blade untuk mengetahui kecepatan spesifik telah dilakukan [10]. Penelitian ini bertujuan untuk mengetahu kecepatan spesifik turbin propeller pada setiap desain dan kondisi lingkungan. Singh juga telah mengevaluasi turbin propeller, dimana salah satu faktor yang mempengaruhi kinerja propeller yaitu sudut kemiringan sudu turbin [11]. Faktor lain yang mempengaruhi performa turbin propeller adalah jumlah sudu turbin dan diameter turbin. Adhikari dalam penelitiannya menghasilkan sebuah desain yang mampu mencapai efisiensi $60 \%$ [12]. Berdarakan studi literatur yang telah dilakukan maka kajian ini bertujuan untuk melakukan analisa terhadap desain geometri sudu turbin propeller agar menghasilkan efisiensi optimal.

\section{Metode Dilakukan}

Metode yang dilakukan dalam paper ini adalah kajian pustaka dan kajian teoritik terhadap variabel yang diteliti. Desain sudu mengacu pada literatur yang telah dirancang menggunakan teori bebas gelembung air, dan beroperasi dengan head dari 1,5 sampai $2 \mathrm{~m}$ dan debit $64 \mathrm{l} / \mathrm{s}$. Variasi sudu adalah sudut kemiringan sudu yang terdiri dari inlet tip angle dan exit tip angle [11]. Jumlah sudu turbin propeller yaitu 5 sudu dengan diameter $h u b$ yaitu $200 \mathrm{~mm}$ [13]. Tujuan penlitian ini adalah untuk mendapatkan desain sudu propeller yang meminimalisir vortek air pada sudu sehingga dapat meningkatkan efisiensi turbin propeller [13]. Gambar 1 berikut menunjukkan desain turbin propeller.

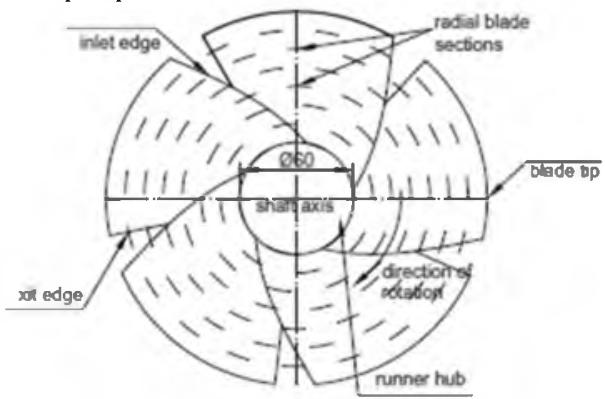

Gambar 1 a Desain propeller [11]

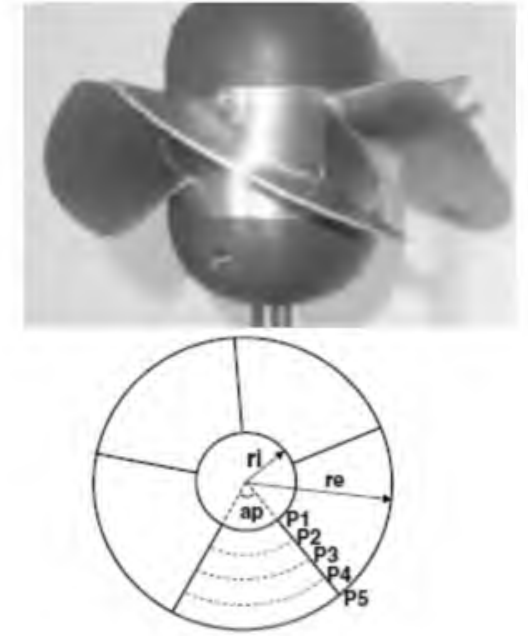

Gambar 1 b Desain propeller [10]

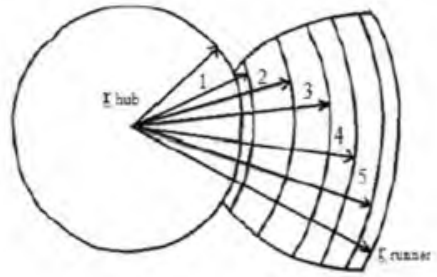

Gambar $1 \mathrm{c}$ Desain propeller [8]

Perhitungan analisa perhitungan potensi daya air yang tersedia digunakan persamaan 1 berikut ini.

$$
P_{f}=\rho Q g H .
$$

Dimana :

$$
\begin{aligned}
& P_{f}=\text { Daya teoritis fluida }(\mathrm{W}) \\
& \rho=\text { Massa Jenis air }\left(\mathrm{kg} / \mathrm{m}^{3}\right) \\
& \mathrm{Q}=\text { Debit air }\left(\mathrm{m}^{3}\right) \\
& \mathrm{g}=\text { Grafitasi Bumi }\left(\mathrm{m} / \mathrm{s}^{2}\right) \\
& \mathrm{H}=\text { Tinggi head }(\mathrm{m})
\end{aligned}
$$

Sedangkan untuk menghitung efisiensi turbin menggunakan persamaan 2 berikut [10].

$$
\eta_{T}=\frac{P_{\text {shaft }}}{P_{f}}
$$

Dimana :

$$
\begin{aligned}
& \eta \quad=\text { Efisiensi Turbin } \\
& P_{\text {shaft }}=\text { Daya Poros }(\mathrm{W}) \\
& P_{f} \quad=\text { Daya teoritis fluida }(\mathrm{W})
\end{aligned}
$$

\section{Hasil Dan Pembahasan}

Inlet tip angle dan exit tip angle adalah parameter yang sangat mempengaruhi efisiensi turbin. Namun, hal mendasar yang perlu dilakukan sebelum merancang variasi desain sudu turbin adalah memahami segitiga kecepatan pada sudu turbin. Gambar 
2 berikut ini mendeskripsikan segitiga kecepatan pada sudu gerak turbin propeller.

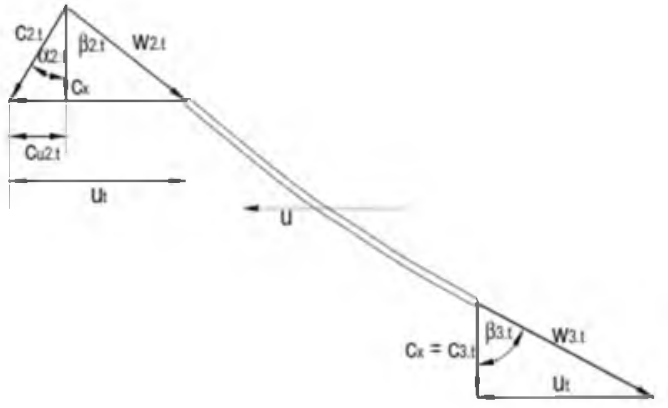

Gambar 2. Segitiga kecepatan sudu turbin

Setelah mengetahui segitiga kecepatan pada sudu gerak turbin, tahap pertama dalam kajian ini yaitu memahami metode pengukuran inlet tip angle untuk menentukan variasi desain sudu propeller. Metode pengukuran ditunjukkan gambar 3 berikut ini.

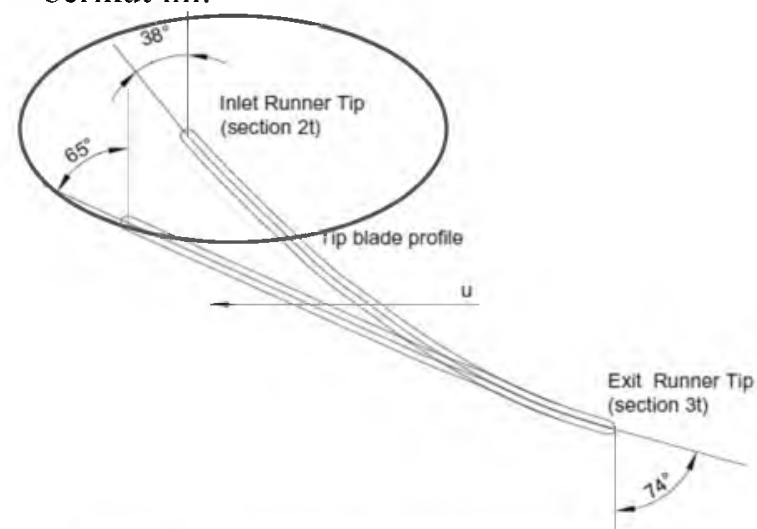

Gambar 3. metode pengukuran inlet tip angle

Gambar 3 menunjukkan modifikasi dan ilustrasi yang mana terdiri dari perubahan besar pada inlet tip angle dari $38^{\circ}$ sampai $65^{\circ}$ (lingkaran merah). Sudut diukur dari referensi garis sumbu sudu propeller. Hasil variasi ini ditunjukkan gambar 4 .

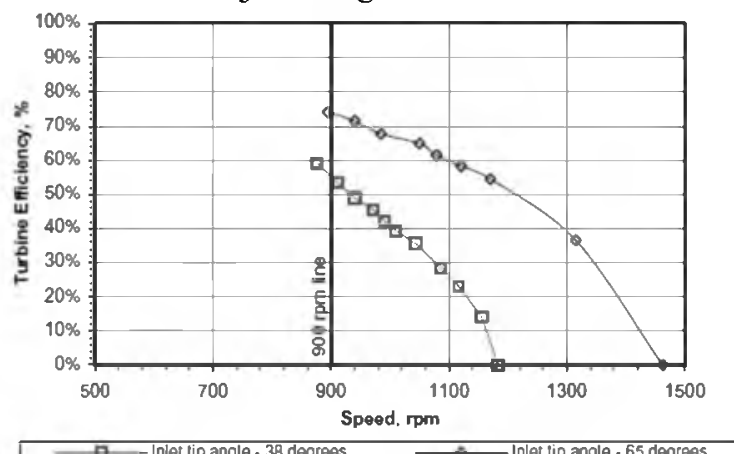

Gambar 4. Grafik efisiensi inlet tip angle pada setiap rpm
Gambar 4 menjelaskan bahwa sudu dengan inlet tip angle $65^{\circ}$ selalu menghasilkan kecepatan putar dan efisiensi yang lebih tinggi dibandingkan dengan inlet tip angle $38^{\circ}$. Pada $900 \mathrm{rpm}$ dan inlet tip angle $65^{\circ}$ turbin mampu menghasilkan efisiensi $74 \%$. Kemudian efisiensi menjadi nol ketika inlet tip angle $38^{\circ}$ mencapai putaran maksimal sebesar $1180 \mathrm{rmp}$ dan inlet tip angle $65^{\circ}$ mencapai putaran maksimal sebesar $1460 \mathrm{rpm}$. Tahap kedua yaitu memahami metode pengukuran exit tip angle. Metode pengukuran ditunjukkan gambar 5 berikut ini.

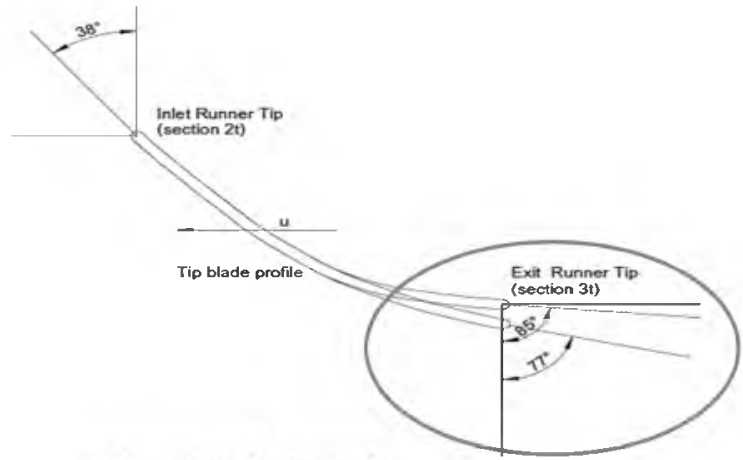

Gambar 5. metode pengukuran exit tip angle

Gambar 5 menunjukkan modifikasi dan ilustrasi yang mana terdiri dari perubahan besar pada exit tip angle dari $85^{\circ}$ sampai $77^{\circ}$ (lingkaran biru). Sudut diukur dari referensi garis sumbu sudu propeller. Hasil variasi ini ditunjukkan gambar 6 .

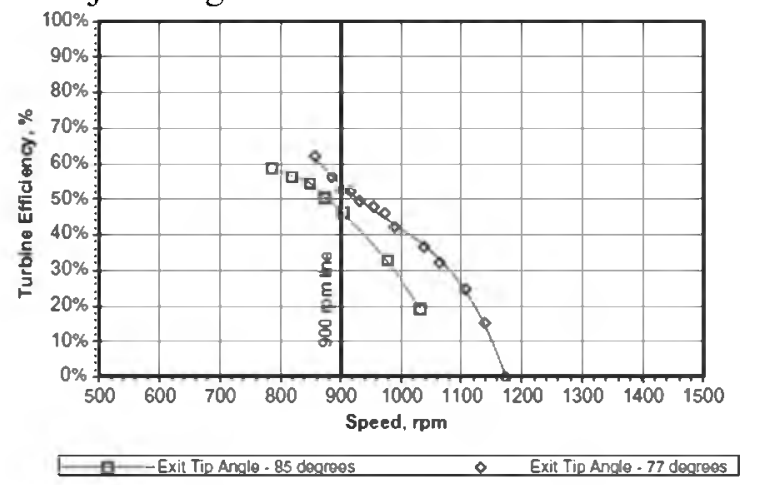

Gambar 6. Grafik efisiensi exit tip angle pada setiap rpm

Gambar 6 menjelaskan bahwa sudu dengan exit tip angle $77^{\circ}$ selalu menghasilkan kecepatan putar dan efisiensi yang lebih tinggi dibandingkan dengan inlet tip angle $85^{\circ}$. Pada $900 \mathrm{rpm}$ dan exit tip angle $77^{\circ}$ turbin mampu menghasilkan efisiensi $54,3 \%$. Kemudian efisiensi menjadi nol 
ketika inlet tip angle $77^{\circ}$ mencapai putaran maksimal sebesar $1180 \mathrm{rmp}$ sedangkan exit tip angle $85^{\circ}$ masih mengkasilkan efisiensi $20 \%$ ketika turbin berputar maksimal yaitu sebesar $1080 \mathrm{rpm}$.

\section{Kesimpulan}

Berdasarkan kajian yang telah dilakukan menyatakan bahwa bentuk sudu propeller berpengaruh terhadap daya shaft turbin. Turbin dengan diameter yaitu $200 \mathrm{~mm}$ dan jumlah sudu propeller 5 menghasilkan daya sebesar 810 Watt. Nilai ini dapat dicapai dengan input debit air 64 1/s dan head 1,75 $\mathrm{m}$. Rancangan desain sudu turbin yang telah dikaji tersebut dapat menaikkan efisiensi turbin shingga $73,9 \%$.

Metode penelitian yang dilakukan Singh relatif lebih mudah digunakan untuk mendesain geometri sudut lengkung sudu turbin propeller. Hal ini dikarenakan referensi titik nol sebagai acuan penentu kelengkungan lebih mudah. Berbeda dengan metode yang dikaji oleh Myint dan Ramos yang menggunakan referensi kelengkungan sudu dengan membagi beberapa badian sudu sehingga diperoleh kelengkungan berdasarkan segitiga kecepatan.

\section{DAFTAR PUSTAKA}

[1] Jurnal Lemhannas RI, 2012, Pengembangan Energi Baru Terbarukan (EBT) guna Penghematan Bahan Baku Fosil dalam Rangka Ketahanan Energi Nasional, Jurnal kajian lemhannas, edisi 14.

[2] Yuningsih, A. dan Masduki, A., 2011, Potensi Energi Arus Laut untuk Pembangkit Tenaga Listrik di Kawasan Pesisir Flores Timur-NTT, Jurnal Ilmu dan Teknologi Kelautan Tropis, Vol. 3, No. 1, Hal. 13-25.

[3] Sarma, N., Biswas, A., \& Misra, R., 2014, Experimental and computational evaluation of Savonius hydrokinetic turbine for low velocity condition with comparison to Savonius wind turbine at the same input power, Energy Conversion and Management, 83, 8898.

[4] H. Zainuddin, M. S. Yahaya, J. M. Lazi, M. F. M. Basar and Z. Ibrahim, 2009, Design and Development of Pico- hydro Generation System for Energy Storage Using Consuming Water Distributed to Houses. World Academy of Science, Engineering and Technology 35 .

[5] K.V. Alexander, E.P. Giddens, A.M. Fuller, 2010, Axial-flow turbines for low head microhydro systems, Renewable Energy 34. Pp. 35-47.

[6] Musa, Masjuri, dkk., 2011, "CFD Analysis on Cost-effective Pico-hydro Turbine: A Case Study for Low Head and Low Flow Rate Condition".

[7] Chen, J., Yang, X.Y., Liu C.P., Lau, C.H., Lo, M., 2013, A novel vertical axis water turbine for power generation from water pipelines, Energy 54, Pp. $184-193$.

[8] Yu War Myint and Htay Htay Win, 2014, "Design and Flow Simulation of Runner Blade for Propeller Turbine".

[9] Nuantong Weerapon, and Taechajedcadarungsri Sirivit, 2009, Flow Simulations on Blades of Hydro Turbine, Khon Kaen University.

[10] Helena M. Ramos, Mariana Simao, and A. Borga, 2013, Experiments and CFD Analyses for a New Reaction Microhydro Propeller with Five Blades, JOURNAL OF ENERGY ENGINEERING, Pp. 109-117.

[11] Punit Singh, Franz Nestmann, 2009, Experimental optimization of a free vortex propeller runner for micro hydro application. Experimental Thermal and Fluid Science 33, Pp. 991-1002.

[12] Pradhumna Adhikari, Umesh Budhathoki, Shiva Raj Timilsina, Saurav Manandhar, Tri Ratna Bajracharya, A Study on Developing Pico Propeller Turbine for Low Head Micro Hydropower Plants in Nepal. Journal of the Institute of Engineering, Vol. 9, No. 1, pp. 36-53.

[13] Pardeep Kumar, R.P. Saini, 2010, Study of cavitation in hydro turbines. Renewable and Sustainable Energy Reviews 14, Pp. 374-383.

[14] Gorlov, A.M., 1998, Development of The Helical Reaction Hydraulic Turbine, Boston, Northeastern University. 